\title{
Rapid PCR/ESI-MS-based molecular genotyping of Staphylococcus aureus from nasal swabs of emergency department patients
}

\author{
Aleksandar Kecojevic ${ }^{1 *}$, Ray Ranken ${ }^{3}$, David J Ecker ${ }^{3}$, Christian Massire $^{3}$, Rangarajan Sampath ${ }^{3}$, Lawrence B Blyn $^{3}$, \\ Yu-Hsiang Hsieh², Richard E Rothman ${ }^{2,4}$ and Charlotte A Gaydos ${ }^{2,4}$
}

\begin{abstract}
Background: A limitation of both culture-based and molecular methods of screening for staphylococcal infection is that current tests determine only the presence or absence of colonization with no information on the colonizing strain type. A technique that couples polymerase chain reaction to mass spectrometry (PCR/ESI-MS) has recently been developed and an assay validated to identify and genotype $S$. aureus and coagulase-negative staphylococci (CONS).

Methods: This study was conducted to determine the rates, risk factors, and molecular genotypes of colonizing Staphylococcus aureus in adult patients presenting to an inner-city academic emergency department. Participants completed a structured questionnaire to assess hospital and community risks for infection with methicillin-resistant S. aureus (MRSA). Nasal swabs were analyzed by PCR/ESI-MS to identify and genotype S. aureus and CoNS.

Results: Of 200 patients evaluated, 59 were colonized with S. aureus; 27 of these were methicillin-resistant strains. Twenty-four of the 59 S. aureus carriers were co-colonized with a CoNS and 140 of the 200 patients were colonized exclusively with CoNS. The molecular genotypes of the 59 S. aureus strains were diverse; 21 unique molecular genotypes belonging to seven major clonal complexes were identified. Eighty-five of 200 patients carried strains with high-level mupirocin resistance. Of these eighty-five participants, 4 were colonized exclusively with S. aureus, 16 were co-colonized with S. aureus and CoNS, and 65 were colonized exclusively with CoNS.

Conclusion: The prevalence of $S$. aureus and methicillin-resistant $S$. aureus colonization in a random sample of patients seeking care in Emergency Department was $29.5 \%$ and $13.5 \%$, respectively. A substantial fraction of the $S$. aureus-colonized patients were co-colonized with CoNS and high-level mupirocin-resistant CoNS. Determining the molecular genotype of $\mathrm{S}$. aureus during intake screening may prove valuable in the future if certain molecular genotypes become associated with increased infection risk.
\end{abstract}

\section{Background}

Staphylococcus aureus is a major cause of healthcareassociated infections [1]. Although several epidemiological studies have provided information on the prevalence of methicillin-resistant Staphylococcus aureus (MRSA) colonization in different hospital settings [2-4] and in emergency department personnel [5,6], limited data exist on MRSA colonization rates for patients seen in emergency departments. The cost benefit of screening

\footnotetext{
* Correspondence: ak955@drexel.edu

'Department of Community Health and Prevention, Drexel University School of Public Health, Philadelphia, PA, USA

Full list of author information is available at the end of the article
}

for MRSA colonization is not overwhelming and the subject is controversial [7]. A limitation of both culturebased and molecular methods of MRSA screening is that current tests determine only the presence or absence of colonization with no information on the colonizing strain type [8]. As only small subsets of MRSA clones have been responsible for the major epidemics in the United States [9] screening might have greater value if future studies demonstrate that certain clones are more likely to cause serious infections than others.

We have developed a rapid molecular surveillance assay based on PCR coupled to electrospray ionization mass spectrometry (PCR/ESI-MS) [10-12] that identifies 
and provides detailed information about $S$. aureus strains. A previous version of this assay has been shown to accurately genotype $S$. aureus strains and to identify the clonal complex of a series of isolates from the Centers for Disease Control (CDC). Excellent agreement with multilocus sequence typing (MLST) and pulsedfield gel electrophoresis (PFGE) results [13] was reached using in the PCR/ESI-MS assay a set of eight primer pairs that target the same genes as those for MLST. This set of primer pairs was designed to optimize the information content of the amplicons and distinguished 99\% of 710 distinct $S$. aureus sequence types [13]. Using a second set of eight primer pairs, PCR/ESI-MS has also been used to characterize virulence factors, toxinencoding genes and antibiotic resistance determinants on isolated colonies [14] and to detect MRSA in nasal swabs with sensitivity and specificity similar to culture methods [15]. In this work, elements from the previous studies were consolidated into a single PCR/ESI-MS research application to directly screen nasal swabs from sample of 200 patients who presented to an urban hospital emergency department.

\section{Methods}

\section{Study setting}

This prospective surveillance study of a convenience sample of adult patients was conducted in the Johns Hopkins Emergency Department, Maryland, from August 2008 to February 2009. The Johns Hopkins Hospital Emergency Department sees approximately 5,000 patients a month. An urgent care center (UCC, 12 beds) and a dedicated 'Short-Stay' emergency acute care unit (EACU, 17 beds) are also part of emergency department services and these patients were included in the study.

\section{Subject selection}

All patients visiting the adult emergency department for evaluation and potential treatment were eligible for the study with the exception of prisoners and patients unable to understand the study requirements. The enrollment of patients was a sample of convenience during hours when the study coordinator was available and included patients seen Monday-Friday during the hours of 9:30 AM5:00 PM. We excluded patients with previously known risk factors for MRSA colonization [16-18] such as patients with fever greater than $100.4^{\circ} \mathrm{F}$, abscesses, cellulitis, infected wounds, and known previous MRSA infections, and history of injection drug use. Three hundred patients were approached for participation; two-thirds of which met all study criteria and ultimately consented to participate in the study. All participants provided verbal informed consent. This study was approved by the Johns Hopkins Institutional Review Board.

\section{Collection of clinical specimens}

Anterior nasal specimens were obtained using BBL Culture Swab Plus double applicators (Becton Dickinson, Sparks, MD) from 200 patients. Swabs were inserted into both left and right nostril of each study subject. One study coordinator collected all specimens.

\section{Analysis of clinical specimens}

Swabs were inoculated into mannitol salts broth and allowed to sit for 5 minutes at room temperature. The swabs were then expressed into broth and incubated at $37^{\circ} \mathrm{C}$ for 4 hours. After this incubation, $300 \mu$ of the sample was added to a tube containing zirconia beads and $200 \mu \mathrm{l}$ of lysis buffer, and the sample was subjected to bead beating for 10 minutes (BioSpec Mini Bead Beater, Bartlesville, OK). Supernatants were transferred to a King Fisher 96well processor and nucleic acids were isolated using the Ambion Total Nucleic acid (TNA) kit (Ambion, Austin, TX). Nucleic acids were analyzed in eight PCR reactions containing the duplex PCR primer pairs (Table 1) on PCR/ ESI-MS platform (available for research applications only; Ibis Biosciences, Abbott, Carlsbad, CA). To determine the methicillin-resistance status of specimens from patients cocolonized with $S$. aureus and CoNS, samples were streaked on a ChromAgar (Becton Dickinson Biosciences, San Jose, $\mathrm{CA})$ plate and incubated for 48 hours at $37^{\circ} \mathrm{C}$.

\section{Staphylococcus aureus genotyping and characterization assay}

In this study we combined elements from the previous genotyping [13] and characterization [14] assays into a single format and added primer pairs to interrogate the gene for toxic shock syndrome toxin 1 (TSST-1) [19], the PVL genes (distinguishing the " $\mathrm{R}$ " and " $\mathrm{H}$ " variants) $[20]$ and the region of the ileS gene that encodes low level mupirocin resistance [21,22]. Thus, the current assay, (Figure 1), used eight amplification/mass spectrometry measurements to simultaneously detect the gene fragments useful for Staphylococcus genotyping and to unambiguously identify $S$. aureus and S. lugdunensis by distinguishing these species from each other as well as other coagulase-negative staphylococcal species. In addition, for S. aureus detections, the presence or absence of PVL (with a distinction between the " $\mathrm{R}$ " and " $\mathrm{H}$ " variants), the mecA gene, the gene encoding TSST-1, and the genes encoding high level (mupA) and low level (ileS) mupirocin resistance were determined along with the clonal complex. The turn-around time of the assay in this study, including the time for analysis was under 8 hours for the first 12 samples. Up to 100 samples can be analyzed in a 24 hours period.

\section{Risk factor evaluation}

A structured nine-item questionnaire was designed based on review of the relevant literature, to identify patient 
Table 1 Primer pairs used in the PCR/ESI-MS MRSA typing and characterization assay

\begin{tabular}{|c|c|c|c|c|c|}
\hline $\operatorname{Row}^{a}$ & $\begin{array}{l}\text { Primer pair } \\
\text { code }\end{array}$ & Target(s) & $\begin{array}{l}\text { Accession number and } \\
\text { coordinates }\end{array}$ & Forward and reverse primer sequences & Reference \\
\hline \multirow[t]{4}{*}{$\bar{A}$} & ВСТ879 & mecA & Y14051 & 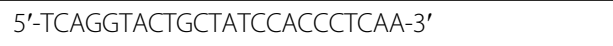 & [14] \\
\hline & & & $4507 . .4581$ & 5'-TGGATAGACGTCATATGAAGGTGTGCT-3' & \\
\hline & BCT2157 & pta & NC_003923 & 5'-TCTTGTTTATGCTGGTAAAGCAGATGG-3' & [13] \\
\hline & & & $629121 . .629229$ & 5'-TGGTACACCTGGTTTCGTTTTGATGATTTGTA-3' & \\
\hline \multirow[t]{4}{*}{ B } & BCT2249 & tufB & NC_002758.2 & 5'-TGAACGTGGTCAAATCAAAGTTGGTGAAGA-3' & [14] \\
\hline & & & $615038 . .616222$ & 5'-TGTCACCAGCTTCAGCGTAGTCTAATAA-3' & \\
\hline & BCT2163 & yqi & NC_003923 & 5'-TGAATTGCTGCTATGAAAGGTGGCTT-3' & [13] \\
\hline & & & 379057..379199 & 5'-TCGCCAGCTAGCACGATGTCATTITC-3' & \\
\hline \multirow[t]{4}{*}{ C } & ВСТ3016 & mupA & X75439 & 5'-TAGATAATTGGGCTCTTTCTCGCTTAAAC-3' & [14] \\
\hline & & & $2482 . .2573$ & 5'-TAATCTGGCTGCGGAAGTGAAAT-3' & \\
\hline & BCT2161 & tpi & NC_003923 & 5'-TCCCACGAAACAGATGAAGAAATTAACAAAAAAG-3' & [13] \\
\hline & & & $830671 . .830799$ & 5'-TGGTACAACATCGTTAGCTITACCACTTTCACG-3' & \\
\hline \multirow[t]{4}{*}{ D } & BCT3106 & TSST1 & NC_002758.2 & 5'-TCGTCATCAGCTAACTCAAATACATGGA-3' & This work \\
\hline & & & 519.620 & 5'-TCACTTTGATATGTGGATCCGTCATTCA-3' & \\
\hline & BCT3025 & $\operatorname{arcc}$ & NC_003923 & 5'-TGAATAGTGATAGAACTGTAGGCACAATCGT-3' & [13] \\
\hline & & & $2724791 . .2724920$ & 5'-TGCGCTAATTCTTCAACTTCTTCTITCGT-3' & \\
\hline \multirow[t]{4}{*}{ E } & BCT2095 & PVL genes, lukE-lukD & NC_003923 & 5'-TGAGCTGCATCAACTGTATTGGATAG-3' & [14] \\
\hline & & & 1529595.1531285 & 5'-TGGAAAACTCATGAAATTAAAGTGAAAGGA-3' & \\
\hline & BCT2149 & $\operatorname{aroE}$ & NC_003923 & 5'-TGGGGCTITAAATATTCCAATTGAAGATTTTCA-3' & [13] \\
\hline & & & 1674546.1674697 & 5'-TACCTGCATTAATCGCTTGTTCATCAA-3' & \\
\hline \multirow[t]{4}{*}{$\mathrm{F}$} & BCT2256 & nuc & NC_002758.2 & 5'-TACAAAGGTCAACCAATGACATTCAGACTA-3' & [14] \\
\hline & & & 894288.894974 & 5'-TAAATGCACTTGCTTCAGGGCCATAT-3' & \\
\hline & BCT2166 & yqi & NC_003923 & 5'-TAGCTGGCGGTATGGAGAATATGTCT-3' & [13] \\
\hline & & & $379190 . .379311$ & 5'-TCCATCTGTTAAACCATCATATACCATGCTATC-3' & \\
\hline \multirow[t]{4}{*}{ G } & BCT4022 & PVL / lukD & NC_003923 & 5'-TGGTCAACAAAGCTATATCAGTGAAGTAGAAC-3' & This work \\
\hline & & & 1529595.1531285 & 5'-TGGATCATGTCCAGACATTTCACCTAATG-3' & \\
\hline & BCT2156 & $g m k$ & NC_003923 & 5'-TCACCTCCAAGTTTAGATCACTTGAGAGA-3' & [13] \\
\hline & & & 1191206..1191337 & 5'-TGGGACGTAATCGTATAAATTCATCATTTC-3' & \\
\hline \multirow[t]{4}{*}{$\mathrm{H}$} & BCT4024 & iles & NC_002758.2 & 5'-TCAGTTGCTACAAGAGGAGTATCACCT-3' & This work \\
\hline & & & 1247700.1250453 & 5'-TACTCATCTTCTTACCTTCACCGTCCATA-3' & \\
\hline & BCT2150 & $\operatorname{aroE}$ & NC_003923 & 5'-TGATGGCAAGTGGATAGGGTATAATACAG-3' & [13] \\
\hline & & & 1674392..1674523' & 5'-TAAGCAATACCTTAACTTGCACCACCTG-3' & \\
\hline
\end{tabular}

${ }^{a}$ Row indicates the row of a 96-well assay plate. Two primer pairs are present in each well of the assay plate.

demographic and other characteristics for hospital and/or community MRSA acquisition. Information collected included patient demographics (age, sex, race), a reason for visit to ED, whether they had a history of prescribed antibiotic, or history of admission to the hospital. Patient medical records were reviewed to provide clarification.

\section{Statistics}

Prevalence estimates were calculated to estimate the proportion of emergency department patients with MRSA colonization. Identification of clinical features associated with MRSA colonization was initially assessed using bivariate analysis. Variables collected on the patient data sheet relating to MRSA colonization were entered into a bivariate logistic regression model to generate odds ratios and corresponding 95\% confidence intervals of these factors, controlling for potential confounders.

\section{Results}

Genotype and characterization analyses

A total of 200 individuals were recruited and met eligibility criteria for this study. Demographic information for the 200 study participants is presented in Table 2. The results for PCR/ESI-MS analysis of nasal swabs 


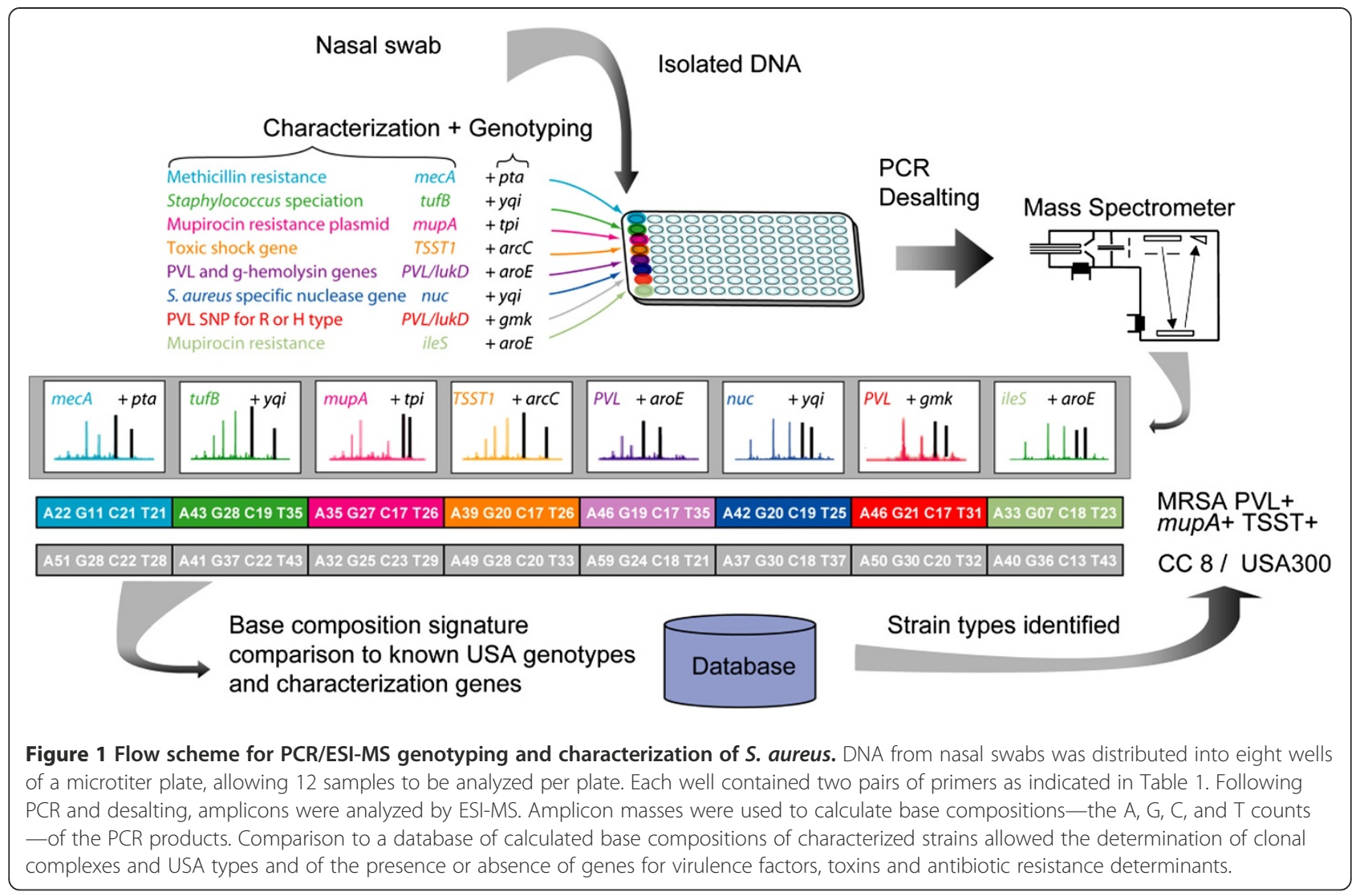

from the participants are illustrated in Figure 2. The primer set used to analyze the nasal swabs contains a primer pair targeted to the highly conserved $t u f B$ gene that amplifies all species within the Staphylococcus genus but not other bacterial genera. Differences in masses of the amplicons in the mass spectra distinguish $S$. aureus and S. lugdunensis from all other species of staphylococci and identify S. aureus and CoNS. When both are present in a patient's sample, spectral peaks from each species are observed in the same spectrum. Similarly, a primer pair targeted to the gmk gene, which is part of the genotyping component of the assay, also amplifies and distinguishes $S$. aureus and CoNS.

Of 200 patients presenting to the emergency department, 59 (29.5\%) were colonized with S. aureus; 24 of these patients were also co-colonized with CoNS (Figure 2). One hundred forty of the 200 (70\%) were colonized exclusively with CoNS. Only one patient showed no evidence of staphylococcal colonization.

The distribution of the $m e c A$ gene (the methicillin resistance gene) and the mupA gene (responsible for high level mupirocin resistance) among the detected Staphylococcus species is also reported in Figure 2. Of 35 patients colonized only with $S$. aureus, 18 were methicillin-sensitive $S$. aureus (MSSA) and 17 were MRSA. Of these 18 MSSA patients,
11.1\% (2/18) were colonized with strains that carried the gene for high-level mupirocin resistance. Of 17 MRSA isolates, $11.8 \%(2 / 17)$ had the mupirocin resistance gene. Of 140 CoNS positive patients, $8.6 \%$ (12/140) were colonized with strains that had only the mupirocin resistance gene, $31.4 \%(44 / 140)$ had only methicillin resistance genes and $37.9 \%$ (53/140) had genes encoding both methicillin and mupirocin resistance.

Among the 24 patients who were co-colonized, 66.7\% $(16 / 24)$ had colonies with both methicillin and high-level mupirocin resistance, while 33.3\% (8/24) had methicillin resistance only. In those co-colonizations, the location of the antibiotic resistance genes could not be determined directly by PCR/ESI-MS (as the same amplicon is produced irrespective of the bacterial strain); instead, the species carrying the gene was determined by plating samples on ChromAgar in order to demonstrate more than one colony type. Since in ten instances methicillin resistance could thus be attributed to $S$. aureus, $45.8 \%$ (27/59) of patients colonized with $S$. aureus were indeed colonized with MRSA. Also, 85 patients altogether were colonized with strains that carried the gene encoding high-level mupirocin resistance.

The genotypes and presence of virulence factors unique to $S$. aureus were determined for all patients 
Table 2 Demographic characteristics of patients $(n=200)$ in the study

\begin{tabular}{|c|c|c|c|}
\hline Variable & $\begin{array}{l}\text { All patients } \\
\text { (200 subjects) }\end{array}$ & $\begin{array}{r}\text { SA carriers } \\
\text { (59 subjects) }\end{array}$ & $\begin{array}{r}\text { MRSA carriers } \\
\text { (27 subjects) }\end{array}$ \\
\hline \multicolumn{4}{|l|}{ Age } \\
\hline $18-29$ & $54(27 \%)$ & $16(27 \%)$ & $7(26 \%)$ \\
\hline $30-39$ & $43(21.5 \%)$ & $15(25.5 \%)$ & $4(15 \%)$ \\
\hline $40-49$ & $55(27.5 \%)$ & $13(22 \%)$ & $9(33 \%)$ \\
\hline $50-59$ & $39(19.5 \%)$ & $13(22 \%)$ & $7(26 \%)$ \\
\hline 60 and up & $9(4.5 \%)$ & $2(3.5)$ & $0(0 \%)$ \\
\hline \multicolumn{4}{|l|}{ Sex } \\
\hline Male & $108(54 \%)$ & $26(44 \%)$ & $15(55 \%)$ \\
\hline Female & $92(46 \%)$ & $33(56 \%)$ & $12(45 \%)$ \\
\hline \multicolumn{4}{|l|}{ Race } \\
\hline White/Hispanic & $38(19 \%)$ & $14(24 \%)$ & $4(15 \%)$ \\
\hline Black & $159(79.5 \%)$ & $45(76 \%)$ & $23(85 \%)$ \\
\hline Asian, Pacific Islander & $2(1 \%)$ & 0 & 0 \\
\hline American Indian Alaskan Native & 0 & 0 & 0 \\
\hline Other & $1(0.5 \%)$ & 0 & 0 \\
\hline \multicolumn{4}{|l|}{ Hispanic/Spanish origin } \\
\hline Yes & $3(1.5 \%)$ & $1(2 \%)$ & 0 \\
\hline No & $195(97.5 \%)$ & $58(98 \%)$ & $27(100 \%)$ \\
\hline Unknown & $2(1 \%)$ & 0 & 0 \\
\hline \multicolumn{4}{|l|}{ Primary complaint } \\
\hline Respiratory & $26(13 \%)$ & $6(10.5 \%)$ & $3(11 \%)$ \\
\hline $\mathrm{Gl}$ & $22(11 \%)$ & $7(12 \%)$ & $3(11 \%)$ \\
\hline Dermatology & $5(2.5 \%)$ & $2(3 \%)$ & $1(4 \%)$ \\
\hline Localized pain/weakness & $87(43.5 \%)$ & $20(35.5 \%)$ & $11(41 \%)$ \\
\hline UGl & $7(3.5 \%)$ & $3(4.5 \%)$ & $1(4 \%)$ \\
\hline Injury & $14(7 \%)$ & $4(6 \%)$ & $2(7.5 \%)$ \\
\hline Cardiovascular & $19(9.5 \%)$ & $8(13.5 \%)$ & $3(11 \%)$ \\
\hline Other & $18(9 \%)$ & $9(15 \%)$ & $3(11 \%)$ \\
\hline General pain/weakness & $2(1 \%)$ & 0 & 0 \\
\hline \multicolumn{4}{|l|}{ Antibiotic prescribed } \\
\hline Yes & $39(19 \%)$ & $8(14 \%)$ & $5(18.5 \%)$ \\
\hline No & $161(79.5 \%)$ & 49 (86\%) & $22(71.5 \%)$ \\
\hline \multicolumn{4}{|l|}{ Admission to hospital } \\
\hline Yes & $29(14.5 \%)$ & $13(22 \%)$ & $7(26 \%)$ \\
\hline No & $171(75.5 \%)$ & $46(78 \%)$ & $20(74 \%)$ \\
\hline
\end{tabular}

colonized with S. aureus, regardless of whether the patient was co-colonized with CoNS. The genotype and characterization results are shown in Table 3. The $59 \mathrm{~S}$. aureus isolates showed a remarkable diversity; the isolates clustered into 21 genotypes as depicted by each unique row in Table 3. One genotype was detected in 12 instances (Table 3) in this patient population, but $11 \mathrm{pa}-$ tients had unique genotypes. When examined from the perspective of clonal complexes, the 21 unique molecular genotypes belong to seven major clonal complexes (CC) (Table 3). The most abundant genotypes were PCR/ESIMS type 1 (CC8) (19 patients), which correlates with USA300, followed by PCR/ESI-MS type 2 (CC5), which correlates with USA100 (12 patients). Eleven patients had genotypes that were PCR/ESI-MS type 1 and were positive for the PVL "R" variant; these genotypes are consistent with the predominant community-associated MRSA (CA-MRSA) in the US [20]. PCR/ESI-MS type 2 


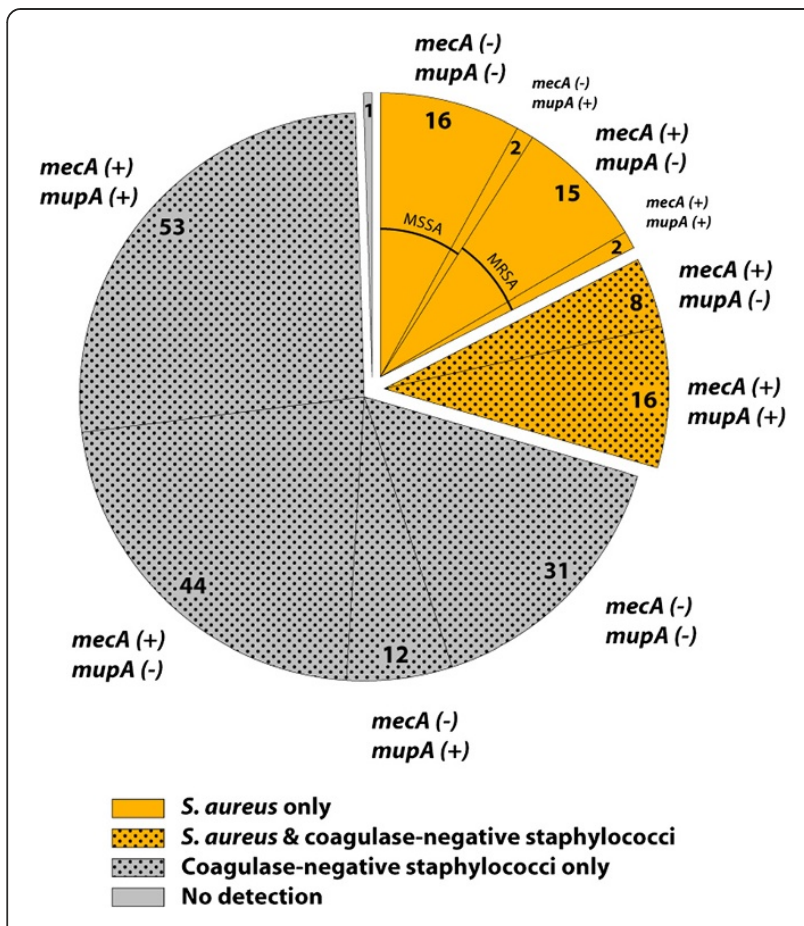

Figure 2 Distribution of S. aureus (orange), coagulase negative staphylococci (stippled) and co-infections of both organisms (orange stippled) within a collection of nasal swabs from 200 patients. Each category is subdivided according to the presence (+) or absence (-) of the mecA and mupA genes, with the indication of the corresponding number of isolates.

(CC5) was isolated from 12 patients; these isolates were PVL negative and these organisms are consistent with hospital-acquired MRSA (HA-MRSA). PCR/ESI-MS types 1 and 2 (CC8 and CC5) represented slightly more than half the organisms isolated from this patient population; the remainders represented a plurality of $\mathrm{CC}$ genotypes (CC45, CC30, CC15, CC45, CC59 or CC1) or did not fit into a previously defined clonal complex (Table 3).

Additional molecular resolution beyond the PCR/ESIMS type was provided by the presence or absence of the $l u k D / E$ genes and the gene encoding the TSST-1 toxin. Regions of two leukocidin toxin-producing operons were amplified by a single pair of primers, BCT2095. A region of the Panton-Valentine leukocidin (PVL) operon, which includes the $l u k S-P V$ and $l u k F-P V$ genes, is targeted by a primer pair that hybridizes across the junction of the 3' end of lukS-PV and the $5^{\prime}$ end of lukF-PV [14]. The same primer pair serendipitously detects and differentiates by virtue of base composition a second leukotoxinencoding operon that contains the $l u k E$ and $l u k D$ genes. Thus, analysis of an isolate had four potential outcomes: PVL positive, lukE/D positive, both positive, or neither positive. The $l u k D / E$ genes are generally correlated with the clonal complex assignment. It was recently shown that the gene encoding TSST-1 protein was associated with PFGE type USA200 in 87\% of isolates studied [23]. The tst gene was present in two of the four instances of this genotype in our study. No mutations associated with low-level mupirocin resistance were observed in the ileS genes within this data set.

\section{Risk factor analysis for colonization}

Patient demographics, primary complaints, antibiotic prescriptions and providers' admission decisions were evaluated for association with particular pathogens. No independent factor was associated with any type of colonization, however African Americans were more likely to be colonized with USA $100 / 300 \mathrm{~S}$. aureus genotypes than other races $(28(62 \%)$ versus $3(21 \%), \mathrm{p}=$ 0.013).

\section{Discussion}

While some Emergency Departments have a high prevalence of MRSA isolated from patients with sporadic skin and soft-tissue infections [24-26], limited research has explored nasal MRSA carriage in this population. The mechanisms leading to $S$. aureus nasal carriage are multifactorial, and an optimal fit between host and bacteria seems to be essential [27]. This study demonstrated a significant prevalence of S. aureus, MRSA and drug-resistant CoNS nasal colonization in a random sample of individuals seeking care from the Emergency Department at The Johns Hopkins Hospital. The prevalence of MRSA (13.5\%) among nasal isolates was somewhat greater than those estimated from other studies that had a similar objective and sample population [28]. Three studies performed outside healthcare facilities (i.e., isolated, semi-closed rural population [29], urban poor in San Francisco [30], or university students in Portugal [31]) that include a total of 4,452 people, showed a pooled MRSA colonization prevalence of only $0.76 \%$ [32]. The prevalence of MRSA colonization in an inpatient setting in a tertiary hospital was reported to be $0.18 \%-7.2 \%$ $[32,33]$. Our findings were similar to the prevalence noted in a study investigating the prevalence of MRSA among newly arrested men in Baltimore $29.5 \%$ and $13.5 \%$ in our study vs. $40.4 \%$ and $15.8 \%$ for S. aureus and MRSA prevalence, respectively) [34]. Other studies have identified three risk factors for MRSA colonization: hospitalization within the past 12 months [16], previous MRSA infection [17] and injection drug use [18]. Because these risk factors had already been identified, they were exclusion criteria in our study. Although we evaluated patient demographics, primary complaints, chronic co-morbidities, antibiotic prescriptions and providers' admission decisions, none were independent risk factors for MRSA colonization. 
Table 3 Determination of PCR/ESI-MS type and clonal complexes of S. aureus from 59 infected patients ${ }^{1}$

\begin{tabular}{|c|c|c|c|c|c|c|}
\hline \multicolumn{2}{|r|}{ Genotype } & \multicolumn{4}{|c|}{ Virulence/Toxin-encoding genes } & \multirow[t]{2}{*}{ Number of instances } \\
\hline Clonal Complex & PCR/ESI-MS or ST Type $e^{2}$ & LUKD/E & $P V L$ & PVL Type & TSST & \\
\hline \multirow[t]{5}{*}{ CC8 } & 1 & - & - & - & - & 1 \\
\hline & & lukD/E+ & - & - & - & 6 \\
\hline & & lukD/E+ & - & - & TSST+ & 1 \\
\hline & & lukD/E+ & PVL+ & R & - & 11 \\
\hline & 7 & lukD/E+ & - & - & - & 1 \\
\hline CC5 & 2 & lukD/E+ & - & - & - & 12 \\
\hline \multirow[t]{2}{*}{ CC30 } & 3 & - & - & - & - & 2 \\
\hline & & - & - & - & TSST+ & 2 \\
\hline CC15 & 12 & lukD/E+ & - & - & - & 4 \\
\hline \multirow[t]{3}{*}{ CC45 } & 6 & lukD/E+ & PVL+ & R & - & 1 \\
\hline & & - & - & - & TSST+ & 1 \\
\hline & & - & - & - & - & 3 \\
\hline CC59 & 5 & - & - & - & - & 3 \\
\hline \multirow[t]{8}{*}{$\mathrm{CC} 1$} & 11 & lukD/E+ & - & - & - & 1 \\
\hline & ST:20 or ST:389 & lukD/E+ & - & - & - & 3 \\
\hline & ST:115, ST:116, or ST:118 & - & - & - & - & 2 \\
\hline & ST:115 & - & - & - & - & 1 \\
\hline & ST:25, ST:28, ST:564, ST:297 or ST369 & lukD/E+ & - & - & - & 1 \\
\hline & ST:109 or ST:540 & - & - & - & - & 1 \\
\hline & ST:630 or ST:683 & - & - & - & - & 1 \\
\hline & ST:188, ST:663 orST:758 & - & - & - & - & 1 \\
\hline
\end{tabular}

'PCR/ESI-MS type and clonal complex correlated as previously described [2].

${ }^{2}$ In cases where the PCR/ESI-MS was not conclusive the best match consistent with ST type is shown.

Our data confirms recent epidemiologic data indicating that nosocomial MRSA strains are present in the community. Interestingly, there was substantial genotypic diversity of $S$. aureus and MRSA types in this the patient population. There was a significant frequency of co-colonization of S. aureus and CoNS (24 patients, 12\%) and at least one third of patients were colonized with a CoNS that had a high-level mupirocin resistance gene (65 patients or $32 \%$, noncounting the $S$. aureus co-infections). This is concerning because it has previously been reported that the gene for high-level mupirocin resistance can be found on conjugative plasmids that carry multiple resistance determinants for other antimicrobial agents [21]. Moreover, this resistance has been shown to be transferable to $S$. aureus [35], which has implications for mupirocin decolonization strategies.

The PCR/ESI-MS methodology operates on an automated, high-throughput platform; patient specimens are screened without culture and results are obtained in a time frame similar to existing molecular tests. As data from more extensive analysis of the $S$. aureus strains that result in the hospital infections become available, additional targets for genetic analysis of $S$. aureus can be added. While a goal of this assay was to add targets that provide information that have value for infection control and tracking outbreaks in hospital settings, the limitation to a current assay is the lack of resolution compared to other technologies. We acknowledge that the inclusion of typing for TSST or PVL, would probably not aid in a clinical scenario, but might aid a research study where predictors of subsequent infection in hospitalized patients were being studied.

This study was performed in one location, the Johns Hopkins Hospital Emergency Department and, therefore, these results may not be applicable to other areas of the United States. Although the ethnic diversity of the study participants was similar to that of the population of Johns Hopkins Hospital patients, of which $80 \%$ are African American, these results may not be applicable to more ethnically diverse areas of the United States. It also should be noted that literature cites significant heterogeneity in the risk factors for nasal S. aureus and MRSA colonization, as well as the fact that only surveying nasal 
swabs likely underestimates the prevalence of S. aureus and MRSA carriage $[4,36]$. Several other, previously described risk factors for S. aureus and MRSA colonization (i.e. previous admission to hospital, or previous antibiotic use) were also investigated in this study. However, there are other known factors for which we do not have data, that might have significantly contributed to the relatively high burden of MRSA encountered in our study, including HIV status, diabetes, men who have sex with men, recent incarceration, high-risk sexual behavior, household members with SSTI, and hospitalassociated exposures [4]. It should be noted that this was not a longitudinal study that would distinguish at least three $S$ aureus nasal carriage patterns in healthy individuals: persistent carriage, intermittent carriage, and non-carriage. This distinction is important because persistent carriers have higher $S$. aureus loads and a higher risk of acquiring S. aureus infection [37,38]. A further important limitation is that in the significant proportion of patients $(\sim 40 \%)$ with both $S$. aureus and CNS, this assay alone cannot distinguish for the presence of MRSA or other resistance determinants being carried by $S$. aureus. Thus, there remains the need for plating samples on ChromAgar, which adds significantly to the turn-around time for infection control purposes.

\section{Conclusions}

In conclusion, the prevalence of $S$. aureus and MRSA colonization in a convenience sample of patients seeking care in Emergency Department was 29.5\% and 13.5\%, respectively. A substantial fraction of the S. aureus-colonized patients were co-colonized with CoNS and highlevel mupirocin-resistant CoNS. These findings highlight the importance of active surveillance studies to detect MRSA colonization and/or infection among emergency department patients. The molecular genotypes were directly identified from nasal swabs by PCR/ESI-MS. The ability to identify unique molecular signatures from MRSA may allow infection control resources to be effectively focused and will enable tracking origins of outbreaks in hospital settings. Determining the molecular genotype of $S$. aureus during intake screening may prove valuable if certain molecular genotypes become associated with increased infection risk.

\begin{abstract}
Abbreviations
PCR/ESI-MS: Polymerase chain reaction to mass spectrometry; CoNS: Coagulase-negative staphylococci; MRSA: Methicillin-resistant Staphylococcus aureus; MLST: Multilocus sequence typing; PFGE: Pulsed-field gel electrophoresis; MSSA: Methicillin-sensitive S. aureus; CC: Clonal complex CA-MRSA: Community-associated MRSA; HA-MRSA: Hospital-acquired MRSA.
\end{abstract}

\section{Competing interests}

Charlotte Gaydos has received funds for speaking and travel from Abbott. Charlotte Gaydos and Richard Rothman have received research funding from Abbott. Ray Ranken, David J. Ecker, Christian Massire, Rangarajan Sampath, and Lawrence B. Blyn are employees of Abbott.

\section{Authors' contributions}

$A K, C G, R R, D J E, R S$, and LBB conceived of the study, and participated in its design and coordination and helped to draft the manuscript. RR and CM carried out the genotyping and characterization assay and drafted the manuscript. Y-HH participated in the design of the study and performed the statistical analysis. All authors read and approved the final manuscript.

\section{Acknowledgments}

The authors thank Dr. Jackie Wyatt, JL-SciEdit for editorial assistance. This study was supported in part by the US Department of Homeland Security through a grant (N00014-06-1-0991) awarded to the National Center for Study of Preparedness and Critical Event Response (PACER) at Johns Hopkins University.

This study has been presented in part at the Society for Academic Emergency Medicine Meeting, Phoenix, AZ, June 3-6, 2010.

\section{Author details}

${ }^{1}$ Department of Community Health and Prevention, Drexel University School of Public Health, Philadelphia, PA, USA. ²Department of Emergency Medicine, School of Medicine, Johns Hopkins University, Baltimore, MD, USA. ${ }^{3}$ Ibis Biosciences, an Abbott Company, Carlsbad, CA, USA. ${ }^{4}$ Department of Medicine, Division of Infectious Diseases, School of Medicine, Johns Hopkins University, Baltimore, MD, USA.

Received: 6 September 2013 Accepted: 6 January 2014

Published: 9 January 2014

\section{References}

1. Klevens RM, Morrison MA, Nadle J, Petit S, Gershman K, Ray S, Harrison LH, Lynfield R, Dumyati G, Townes JM, et al: Invasive methicillin-resistant Staphylococcus aureus infections in the United States. JAMA 2007 298(15):1763-1771.

2. Muralidhar B, Anwar SM, Handa Al, Peto TE, Bowler IC: Prevalence of MRSA in emergency and elective patients admitted to a vascular surgical unit: implications for antibiotic prophylaxis. Eur J Vasc Endovasc Surg 2006, 32(4):402-407

3. Hammond CJ, Gill J, Peto TE, Cadoux-Hudson TA, Bowler IC: Investigation of prevalence of MRSA in referrals to neurosurgery: implications for antibiotic prophylaxis. Br J Neurosurg 2002, 16(6):550-554.

4. Peters PJ, Brooks JT, McAllister SK, Limbago B, Lowery HK, Fosheim G, Guest J, Gorwitz RJ, Bethea M, Hageman J, Mindley R, McDougal LK, Rimland D: Methicillin-resistant Staphylococcus aureus colonization of the groin and risk for clinical infection among HIV-infected adults. Emerg Infect Dis 2013, 19(4):623-629.

5. Suffoletto BP, Cannon EH, Ilkhanipour K, Yealy DM: Prevalence of Staphylococcus aureus nasal colonization in emergency department personnel. Ann Emerg Med 2008, 52(5):529-533.

6. Bisaga A, Paquette K, Sabatini L, Lovell EO: A prevalence study of methicillin-resistant Staphylococcus aureus colonization in emergency department health care workers. Ann Emerg Med 2008, 52(5):525-528.

7. Peterson LR, Diekema DJ: To screen or not to screen for methicillinresistant Staphylococcus aureus. J Clin Microbiol 2010, 48(3):683-689.

8. Peterson LR, Liesenfeld O, Woods CW, Allen SD, Pombo D, Patel PA, Mehta MS, Nicholson B, Fuller D, Onderdonk A: Multicenter evaluation of the LightCycler(R) MRSA advanced test as a rapid method for detection of Methicillin-resistant Staphylococcus aureus (MRSA) in nasal surveillance swabs. J Clin Microbiol, 48(5):1661-1666.

9. Brady JM, Stemper ME, Weigel A, Chyou PH, Reed KD, Shukla SK: Sporadic "transitional" community-associated methicillin-resistant Staphylococcus aureus strains from health care facilities in the United States. J Clin Microbiol 2007, 45(8):2654-2661.

10. Sampath R, Hofstadler SA, Blyn L, Eshoo M, Hall T, Massire C, Levene H, Hannis J, Harrell PM, Neuman B, et al: Rapid identification of emerging pathogens: coronavirus. Emerg Infect Dis 2005, 11(3):373-379.

11. Hofstadler SA, Sampath R, Blyn LB, Eshoo MW, Hall TA, Jiang Y, Drader Jر, Hannis JC, Sannes-Lowery KA, Cummins LL, et al: TIGER: the universal biosensor. Inter J Mass Spectrom 2005, 242:23-41.

12. Ecker DJ, Sampath R, Blyn LB, Eshoo MW, Ivy C, Ecker JA, Libby B, Samant V, Sannes-Lowery K, Melton RE, et al: Rapid identification and strain-typing of respiratory pathogens for epidemic surveillance. Proc Natl Acad Sci USA 2005, 102(22):8012-8017 
13. Hall TA, Sampath R, Blyn LB, Ranken R, Ivy C, Melton R, Matthews H, White $\mathrm{N}$, Li F, Harpin V, et al: Rapid molecular genotyping and clonal complex assignment of S. aureus isolates by PCR/ESI-MS. J Clin Microbiol 2009, 47(6):1733-1741.

14. Wolk DM, Blyn LB, Hall TA, Sampath R, Ranken R, Ivy C, Melton R, Matthews $H$, White $N$, Li F, et al: Pathogen profiling: rapid molecular characterization of Staphylococcus aureus by PCR/ESI-MS and correlation with phenotype. J Clin Microbiol 2009, 47(10):3129-3137.

15. Sampath R, Blyn L, Ranken R, Massire C, Hall TA, Eshoo MW, Li F, Lovari R, Frinder M, Matthews $H$, et al: Rapid detection and characterization of five important microbes that cause HealthCare-associated infections using PCR/ESI-MS. In 19th Annual Scientific Meeting of The Society for Healthcare Epidemiology of America (SHEA): March 19-22, 2009 2009. San Diego, CA: Sheraton San Diego Hotel \& Marina; 2009.

16. Sumrall B, Nolan R: Retrospective study of "community-acquired" (CA) methicillin-resistant Staphylococcus aureus (MRSA) occurring during and epidemic of MRSA at a Veteran Affairs hospital (abstract 78). Infect Control Hosp Epidemiol 1996, 17(suppl):28.

17. Warshawsky B, Hussain Z, Gregson DB, Alder R, Austin M, Bruckschwaiger D, Chagla AH, Daley J, Duhaime C, MCGhie K, et al: Hospital- and communitybased surveillance of methicillin-resistant Staphylococcus aureus: previous hospitalization is the major risk factor. Infect Control Hosp Epidemiol 2000, 21(11):724-727.

18. Berman DS, Schaefler S, Simberkoff MS, Rahal JJ: Staphylococcus aureus colonization in intravenous drug abusers, dialysis patients, and diabetics. J Infect Dis 1987, 155(4):829-831.

19. Schmitz FJ, Steiert M, Hofmann B, Verhoef J, Hadding U, Heinz HP, Kohrer K: Development of a multiplex-PCR for direct detection of the genes for enterotoxin B and C, and toxic shock syndrome toxin-1 in Staphylococcus aureus isolates. J Med Microbiol 1998, 47(4):335-340.

20. O'Hara FP, Guex N, Word JM, Miller LA, Becker JA, Walsh SL, Scangarella NE, West JM, Shawar RM, Amrine-Madsen H: A geographic variant of the Staphylococcus aureus Panton-Valentine leukocidin toxin and the origin of community-associated methicillin-resistant S. aureus USA300. J Infect Dis 2008, 197(2):187-194.

21. Patel JB, Gorwitz RJ, Jernigan JA: Mupirocin resistance. Clin Infect Dis 2009, 49(6):935-941

22. Antonio M, McFerran N, Pallen MJ: Mutations affecting the Rossman fold of isoleucyl-tRNA synthetase are correlated with low-level mupirocin resistance in Staphylococcus aureus. Antimicrob Agents Chemother 2002, 46(2):438-442

23. Limbago B, Fosheim GE, Schoonover V, Crane CE, Nadle J, Petit S, Heltzel D, Ray SM, Harrison LH, Lynfield R, et al: Characterization of methicillinresistant Staphylococcus aureus isolates collected in 2005 and 2006 from patients with invasive disease: a population-based analysis. J Clin Microbiol 2009, 47(5):1344-1351.

24. Frazee BW, Lynn J, Charlebois ED, Lambert L, Lowery D, PerdreauRemington F: High prevalence of methicillin-resistant Staphylococcus aureus in emergency department skin and soft tissue infections. Ann Emerg Med 2005, 45(3):311-320.

25. Moran GJ, Amii RN, Abrahamian FM, Talan DA: Methicillin-resistant Staphylococcus aureus in community-acquired skin infections. Emerg Infect Dis 2005, 11(6):928-930.

26. Talan DA, Krishnadasan A, Gorwitz RJ, Fosheim GE, Limbago B, Albrecht V, Moran GJ, EMERGEncy ID Net Study Group: Comparison of Staphylococcus aureus from skin and soft-tissue infections in US emergency department patients, 2004 and 2008. Clin Infect Dis 2011, 53(2):144-149.

27. Wertheim HF, Melles DC, Vos MC, van Leeuwen W, van Belkum A, Verbrugh HA, Nouwen JL: The role of nasal carriage in Staphylococcus aureus infections. Lancet Infect Dis 2005, 5(12):751-762.

28. Graham PL 3rd, Lin SX, Larson EL: A U.S. population-based survey of Staphylococcus aureus colonization. Ann Intern Med 2006, 144(5):318-325.

29. Eicher KL, Hiatt D, Johnson D, Kaplan E: The epidemiology of methicillinresistant Staphylococcus aureus (MRSA) in a relatively isolated, semiclosed rural population: comparing clonality among isolates from normal school children, hospital personnel, and hospital laboratory isolates. In Abstracts of the 38th Annual Meeting of the Infectious Diseases Society of America. Alexandria, VA: Infectious Diseases Society of America; 2000:127.

30. Charlebois ED, Bangsberg DR, Moss NJ, Moore MR, Moss AR, Chambers HF, Perdreau-Remington F: Population-based community prevalence of methicillin-resistant Staphylococcus aureus in the urban poor of San Francisco. Clin Infect Dis 2002, 34(4):425-433.

31. Sa-Leao R, Sanches IS, Couto I, Alves CR, de Lencastre H: Low prevalence of methicillin-resistant strains among Staphylococcus aureus colonizing young and healthy members of the community in Portugal. Microb Drug Resist 2001, 7(3):237-245

32. Salgado CD, Farr BM, Calfee DP: Community-acquired methicillin-resistant Staphylococcus aureus: a meta-analysis of prevalence and risk factors. Clin Infect Dis 2003, 36(2):131-139.

33. Barakate MS, Yang YX, Foo SH, Vickery AM, Sharp CA, Fowler LD, Harris JP, West RH, Macleod C, Benn RA: An epidemiological survey of methicillinresistant Staphylococcus aureus in a tertiary referral hospital. J Hosp Infect 2000, 44(1):19-26.

34. Farley JE, Ross T, Stamper P, Baucom S, Larson E, Carroll KC: Prevalence, risk factors, and molecular epidemiology of methicillin-resistant Staphylococcus aureus among newly arrested men in Baltimore, Maryland. Am J Infect Control 2008, 36(9):644-650.

35. Perez-Roth E, Lopez-Aguilar C, Alcoba-Florez J, Mendez-Alvarez S: High-level mupirocin resistance within methicillin-resistant Staphylococcus aureus pandemic lineages. Antimicrob Agents Chemother 2006, 50(9):3207-3211.

36. Forster AJ, Oake N, Roth V, Suh KN, Majewski J, Leeder C, van Walraven C: Patient-level factors associated with methicillin-resistant Staphylococcus aureus carriage at hospital admission: a systematic review. Am J Infect Control 2013, 41(3):214-220.

37. White A: Increased infection rates in heavy nasal carriers of coagulasepositive Staphylococci. Antimicrob Agents Chemother (Bethesda) 1963, 161:667-670.

38. Nouwen JL, Fieren MW, Snijders S, Verbrugh HA, van Belkum A: Persistent (not intermittent) nasal carriage of Staphylococcus aureus is the determinant of CPD-related infections. Kidney Int 2005, 67(3):1084-1092.

doi:10.1186/1471-2334-14-16

Cite this article as: Kecojevic et al:: Rapid PCR/ESI-MS-based molecular genotyping of Staphylococcus aureus from nasal swabs of emergency department patients. BMC Infectious Diseases 2014 14:16.

\section{Submit your next manuscript to BioMed Central and take full advantage of:}

- Convenient online submission

- Thorough peer review

- No space constraints or color figure charges

- Immediate publication on acceptance

- Inclusion in PubMed, CAS, Scopus and Google Scholar

- Research which is freely available for redistribution

Submit your manuscript at www.biomedcentral.com/submit
C) BioMed Central 